2011

\title{
Cointegrating Institutions: The Time-Series Properties of Country Institutional Measures
}

Russell S. Sobel

Christopher J. Coyne

Follow this and additional works at: https://researchrepository.wvu.edu/faculty_publications

\section{Digital Commons Citation}

Sobel, Russell S. and Coyne, Christopher J., "Cointegrating Institutions: The Time-Series Properties of Country Institutional Measures" (2011). Faculty Scholarship. 85.

https://researchrepository.wvu.edu/faculty_publications/85 


\title{
Cointegrating Institutions: The Time-Series Properties of Country Institutional Measures
}

\author{
Russell S. Sobel West Virginia University \\ Christopher J. Coyne George Mason University
}

\begin{abstract}
A country's political and economic institutions are critical for economic prosperity. The literature abounds with institutional measures, precisely because institutions are multidimensional. We use panel unit root and cointegration tests to examine the time-series properties of several institutional measures to answer two questions. First, do institutional changes tend to be permanent? Second, which subsets of institutions tend to converge or move together? These answers have important implications for whether permanent institutional reform is possible and whether reforms can be undertaken one institutional area at a time or instead must simultaneously encompass multiple institutional areas.
\end{abstract}

\section{Introduction}

What explains why some countries grow prosperous while others do not? This question has been at the heart of economic inquiry since the publication of Adam Smith's An Inquiry into the Nature and Causes of the Wealth of Nations. He concluded, "Little else is requisite to carry a state to the highest degree of opulence from the lowest barbarism, but peace, easy taxes, and a tolerable administration of justice; all the rest being brought about by the natural course of things" (Smith [1776] 1904, p. I.56). ${ }^{1}$ Smith was highlighting the importance of rules, or institutions, for economic outcomes. The importance of institutions for economic performance received renewed focus with the rise of the new institutional economics in the 1960s. During this period, the pioneering work of such scholars as Ronald Coase, Harold Demsetz, and Douglass North led to a resurgence in the idea that a country's institutions are primarily responsible

The authors thank Arabinda Basistha, an anonymous referee, and the editors for helpful comments, discussion, and suggestions. Dashle Kelley provided valuable research assistance. We gratefully acknowledge the financial support of the Kendrick Fund.

${ }^{1}$ This quote is originally attributed to Smith in 1755 by Stewart (1793). 
for economic prosperity. In this literature, institutions are broadly defined as the formal and informal rules of the game governing interactions among individuals (North 1990, 1991).

According to Matthews (1986, p. 903), the emergence of new institutional economics led to a twofold realization: "institutions do matter, [and] the determinants of institutions are susceptible to analysis by the tools of economic theory." Indeed, a large empirical literature clearly demonstrates the link between prosperity and institutions, using a variety of measures (see, for example, Barro 1996; Aron 2000; Acemoglu, Johnson, and Robinson 2001, 2002; Glaeser et al. 2004; Rodrik, Subramanian, and Trebbi 2004; Acemoglu and Johnson 2005; Gwartney, Lawson, and Holcombe 1999; Ovaska and Sobel 2005; Sobel, Clark, and Lee 2007). Although we know that institutions matter for economic outcomes, an important area of inquiry that remains underexplored is the interrelationships among the many different political and economic institutions. Notable scholars, such as F. A. Hayek (1944) and Milton Friedman (1962), have postulated that a country's political and economic institutions tend to be interrelated. More specifically, they argue that sustainable political freedoms require economic freedoms. Understanding the interrelationship between economic and political institutions was also a central issue in transition economies where policy makers attempted to reform both institutional areas simultaneously after the collapse of communism (Kornai 1992, 1998). The varying economic and political performance of transition countries indicates that we lack a firm understanding of the complex interplay between institutional areas.

Critical to understanding the relationship between political and economic institutions is the important distinction between formal and informal institutions. Examples of formal rules include codified legal and political structures and written rules such as constitutions. Informal rules include culture, norms, conventions, and mores not backed by formal law but rather by social custom. Institutions provide the general rules of the game that facilitate economic, social, and political interactions. In providing the rules of the game, institutions establish or alter incentives by influencing the costs and benefits associated with certain types of activities.

An existing literature argues that in order for formal institutions to stick, they must be grounded in informal institutions (de Soto 1989; Boettke, Coyne, and Leeson 2008; Williamson 2009). This indicates that informal institutions underlie certain types of formal institutional arrangements. Although formal institutions can be changed statutorily, constitutionally, or through other democratic (or nondemocratic) methods, informal institutions tend to change slowly because they are embedded in culture, norms, and traditions (Williamson 2000; North 2005). Informal institutions are also important in facilitating interaction where formal institutions are absent or dysfunctional (Anderson and Hill 2004; Dixit 2004; Leeson 2007, 2008, 2009). In its entirety, this body of research implies that informal institutions may be more permanent and, also, that because formal institutions evolve within the context of a given set of existing informal insti- 
tutions, a country's many formal political and economic institutions are likely to be interrelated as a result of their common foundation.

The question we set out to address in this paper is whether a country's many political and economic institutions are interrelated. Along the way, we also ask other questions, including whether institutional changes tend to be permanent or whether institutional reforms tend to erode through time until a country is back where it started. We consider several well-known measures of political and economic institutions and use modern time-series techniques that allow the use of panel data to test for stationarity and cointegration. The use of panel timeseries techniques, as compared to cross-sectional analysis, allows for analysis of related variables even though they might be shocked out of their long-term relationships in the short run.

Whether a particular institutional measure is stationary determines whether or not changes in that institutional structure are permanent. Whether a pair of institutions are cointegrated determines whether they tend to move together (that is, whether they remain convergent), in that changes in one will stick permanently only if the other institution is reformed as well. We use the hierarchy of social analysis of Williamson (2000) to interpret our results. This hierarchy provides an analytical framework for understanding the relationship between different institutions.

Our analysis provides evidence that formal political and economic institutions are nonstationary, implying that institutional reforms are indeed permanent. We also find that the two measures of rights-based institutions-civil liberties and political rights - are stationary, or mean reverting. This is likely because these measures capture elements of informal institutions that are more permanent and embedded in a society's culture. In addition, we find strong evidence that most measures of a country's institutions are cointegrated, implying that institutional reforms will work only if they simultaneously encompass a broad range of different institutions. This has important implications for our understanding of how institutions relate because although we know that institutions matter, they cannot be considered in isolation. Political and economic institutions tend to move together, and reforms in one without simultaneous reforms in related institutions will fail to be sustaining over time. Focus must be placed on understanding how and if reforms across multiple institutions can be effectively undertaken at the same time.

We proceed as follows. Section 2 reviews the previous and related literature on institutions. Section 3 outlines the time-series tests that we conduct and discusses how they relate to interesting questions about a country's institutions (and changes in them through time). Section 4 introduces several well-known empirical measures of a country's institutions. Section 5 tests for stationarity in each measure, and Section 6 tests for cointegration across the measures. Section 7 concludes. 


\section{Literature Review}

The importance of institutions for economic outcomes received renewed focus with the emergence of the new institutional economics in the 1960s. Several important works provided the foundations of this literature. Coase's seminal paper (1960) shifted the discussion of externalities from standard welfare economics to a consideration of comparative institutional arrangements. Demsetz (1967) studied the emergence and evolution of institutional arrangements and concluded that institutions would emerge where there was a net benefit to their existence and where transaction costs were not prohibitively high. North and Thomas (1973) explored the connection between changes in institutions and such variables as population growth and political rents. Williamson's (1975) work on the economics of the firm also brought increasing attention to the importance of institutions and organizations.

Williamson's (2000, pp. 596-600) hierarchy of levels of social analysis provides insight into the role of institutions in economic analysis. This hierarchy is illustrated in Table 1. The higher the level of social analysis, the more permanent are the associated characteristics and, hence, the slower the rate of change. Further, each level imposes constraints on the levels below it. For example, a society's embedded informal institutions (level 1), which can take from 100 to 1,000 years to change, will constrain the nature of the formal rules of the game (level 2). The formal rules in turn constrain the interactions that take place within those institutions (level 3), which ultimately affect the allocation of resources (level 4). Williamson's hierarchy provides insight into the various levels of social analysis and how institutions relate to one another. As we discuss in subsequent sections, we use a variety of institutional measures that can be mapped to the various levels in Williamson's hierarchy.

Numerous quantitative studies explore the role of formal institutions in economic performance (Aron 2000). Barro (1996) analyzes the relationship between democracy and economic growth and finds a nonlinear relationship: democracy enhances growth at low levels of political freedom but hurts growth once some moderate level of political freedom exists. Acemoglu, Johnson, and Robinson $(2001,2002)$ consider the role of institutions in economic performance and find that private-property institutions are the main determinant of economic performance. Rodrik, Subramanian, and Trebbi (2004) empirically analyze the effect of institutions, geography, and trade on income and find that institutions trump geography and trade in explaining differences in income across countries. ${ }^{2}$ Acemoglu and Johnson (2005) unbundle property institutions. They differentiate between contracting institutions (for example, courts), which enforce agreements between private citizens, and property rights institutions, which protect citizens from government expropriation. They find that property rights institutions are more important than contracting institutions for economic performance. Easterly

\footnotetext{
${ }^{2}$ There is an ongoing debate regarding the primacy of institutions over geography for explaining economic development (Sachs and Warner 2001; Sachs 2003; Gallup, Sachs, and Mellinger 1999).
} 
Table 1

Williamson's Hierarchy of Social Analysis

\begin{tabular}{llc}
\hline Level & \multicolumn{1}{c}{ Description } & Time to Change \\
\hline 1 & $\begin{array}{c}\text { Embeddedness: informal institutions, customs, traditions, norms, and } \\
\text { religion }\end{array}$ & $100-1,000$ years \\
2 & $\begin{array}{c}\text { Institutional environment: formal rules of the game, especially property } \\
\text { (polity, judiciary, and bureaucracy) }\end{array}$ & $10-100$ years \\
3 & $\begin{array}{c}\text { Governance: play of the game, especially contract (aligning governance } \\
\text { structure with transactions) }\end{array}$ & $1-10$ years \\
4 & $\begin{array}{l}\text { Resource allocation and employment (prices and quantities, incentive } \\
\text { alignment) }\end{array}$ & Continuous \\
\hline
\end{tabular}

(2001) finds that high-quality institutions can overcome ethnic tensions and conflict. Mehlum, Moene, and Torvik (2006) find that the quality of institutions is the driving factor behind whether an abundance of natural resources contributes to economic growth or stagnation.

More recently, increasing focus has been placed on how informal institutions influence the process of economic change and the resulting economic outcomes. De Soto (1989) analyzes the clash between formal and informal institutions in Peru and concludes that although informal institutions facilitate cooperation in the underground economy, development is limited because of constraints created by formal institutions. To better understand informal institutions, North (2005) incorporates belief systems and cognitive elements in his analysis of institutional evolution and change. Knack and Keefer (1997) provide empirical evidence that social capital, measured through indicators of trust and civic norms, matters for economic outcomes. Grier (1997) and Barro and McCleary (2003) explore the connection between religion and economic growth, while Guiso, Sapienza, and Zingales (2006) analyze the impact of culture on economic outcomes. Williamson (2009) finds that informal institutions constrain formal institutions and therefore are an important determinant of economic development.

We contribute to this existing literature on the importance of institutions for economic outcomes by exploring if and how political and economic institutions are related. In doing so, we also provide insight into which institutional changes tend to be permanent and which are only temporary. This is important for understanding if and how institutional areas can be reformed.

\section{Panel Unit Root and Cointegration Testing}

Consider an individual time-series variable, $Y_{t}$, that evolves through time according to the following equation:

$$
Y_{t}=\alpha+\beta \times Y_{t-1}+\varepsilon_{1} .
$$

The variable $Y_{t}$ is said to be stationary if, when shocked, it tends to revert to a prior, time-invariant mean level. This will be true if the coefficient on the lagged value of $\beta$ is less than 1 . If, instead, $\beta$ is equal to or greater than 1 , the series 


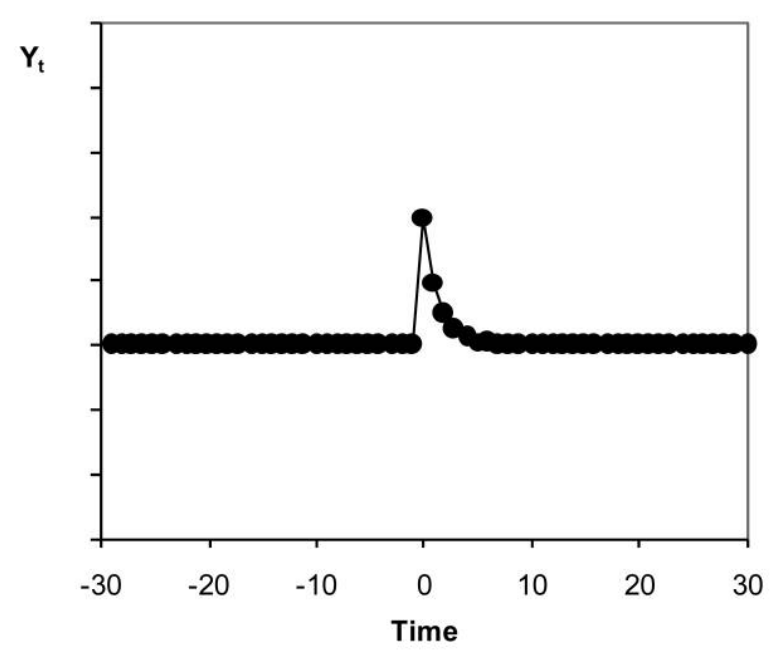

Figure 1. Response of a stationary time series to a one-time shock

is nonstationary, which means that it has a unit root. A nonstationary series does not have a permanent mean level; rather, any changes are permanently incorporated into the level of the series. Even readers who are unfamiliar with the time-series literature will likely know one example of a nonstationary process: the random walk. ${ }^{3}$ This is the case when, in equation (1), $\alpha=0$ and $\beta=1$, producing

$$
Y_{t}=Y_{t-1}+\varepsilon_{t} .
$$

With the dynamics produced by equation (2), all changes are permanent, and the level of the variable will tend to remain at its level from the previous period, permanently incorporating any changes introduced through shocks, $\varepsilon_{t}$. This difference can be seen in Figures 1 and 2.

Figure 1 shows an example of how a stationary time series responds to a onetime change. Here, a change eventually decays, and the series returns to its prior level. Figure 2 shows how a nonstationary time series responds to a one-time change. This time, the change is permanently incorporated into the level of the series.

Applying this concept to international measures of institutions allows us to estimate whether, for each measure, changes to the series remain permanent. For example, the United States has recently devoted substantial resources to intervention in Iraq that is meant to permanently reform the country's political

${ }^{3}$ For a good overview of basic time-series properties, including stationarity and cointegration, see Greene (2008). 


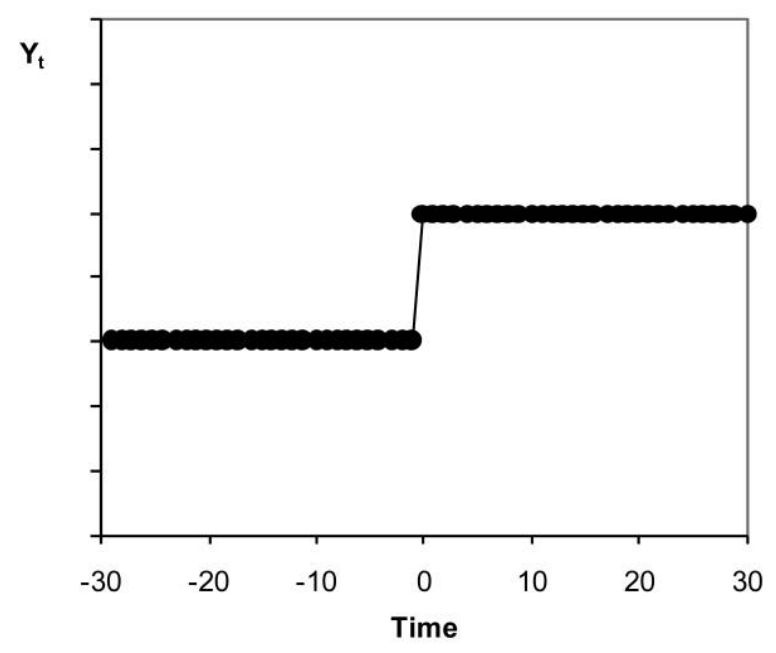

Figure 2. Response of a nonstationary time series to a one-time shock

institutions. If successful, the important question remains whether, after the occupation ends, Iraq's new institutions will persist or will decay to their original level.

Testing for stationarity can be done using several different tests that use slightly different methods. We perform the entire battery of tests with our data to see which institutional measures exhibit stationarity and which do not.

Although stationarity is a property of an individual time series, cointegration refers to a relationship among two or more different nonstationary time series. In a broad sense, if two series are cointegrated, they tend to move back together after being shocked apart. More technically, if $X_{t}$ and $Y_{t}$ denote two nonstationary time-series variables, define a new variable, $Z_{t}$, that is the following linear combination of $X_{t}$ and $Y_{t}$ :

$$
Z_{t}=\alpha+\beta_{1} \times Y_{t}-\beta_{2} \times X_{t}+\varepsilon_{t}
$$

The new series, $Z_{t}$, essentially represents the difference between the series. If the two are cointegrated and tend to be convergent through time, then the variable $Z_{t}$ will be stationary. If the two tend to drift apart or are not convergent, then $Z_{t}$ will be nonstationary.

Applying this concept to international measures of institutions allows us to estimate whether it is possible to reform specific individual institutions without the necessity of reforming others. If two institutions are cointegrated, a change in one will be permanent only if both change. In other words, a reform to only one will be meaningless in the long run because it will be pulled back to the long-term path determined by the other institution(s). 
If they are not cointegrated, each can be individually changed independent of changes to the other. This would imply that reforms can be made to institutions successfully even if only one institution is altered. Just as with stationarity, we present several different tests of cointegration, using slightly different methodologies, for our variables measuring institutions.

Until recently, such estimation would not have been possible. Traditionally, these tests are conducted on data spanning a long period, using, for example, two series for the same country. Unfortunately, most indices of institutional quality are fairly recent, and many span only a limited historical period, sometimes in 5-year intervals. Because of this lack of length in the data, these timeseries tests would be impossible to perform for a given country. Recently, however, methods have been developed that allow the use of combined cross-section and time-series data that allow this type of testing to be conducted for panel data. In essence, panel unit root and cointegration testing exploits both the crosssectional and time-series components of the data to allow enough observations on which to conduct testing.

The benefit of using panel time-series techniques over simple cross-sectional analysis is that they allow for variables to be related over long time horizons, even though they may be shocked out of this long-term relationship for shortterm periods. These short-term distortions are problematic for cross-sectional analyses, particularly those performed on the first difference or change in the variables. For example, if $X_{t}$ and $Y_{t}$ are cointegrated but get shocked apart, when they are coming back together we would witness $X_{t}$, say, falling while $Y_{t}$ is simultaneously rising as the two attempt to get back to their long-term cointegrating path. Therefore, it is possible to pick up negative correlations in crosssectional analysis of $\Delta Y_{t}$ and $\Delta X_{t}$ when the relationship between the two variables is, instead, a true positive relationship over a long time horizon.

In addition, because there will be wide variation across countries in the degree to which $X_{t}$ and $Y_{t}$ are shocked apart in a given year, a single cross section will see a more widely disbursed cloud of data, increasing the standard errors of the regression and potentially creating bias as the regression line tries to fit outlier observations. For example, if democracy and capitalism are cointegrated, then they will stay together in the long run, but it will still be possible to witness many observations that may be contrary to this (that is, way off the true regression line) in any one period in a cross section of countries. Therefore, it may look as if there are many counterexamples to the pairing of democracy and capitalism in any given year, despite the presence of a long-term positive association between the two. Panel time-series techniques properly account for these dynamics and are therefore a better way to test for true relationships among a country's institutions.

\section{Institutional Measures}

Our analysis relies on seven well-known measures of political and economic institutions, summarized in Table 2. All indices are collected at 5-year intervals 
(1970-2005) whenever they are present. We made an attempt to include as many popular institutional measures as possible, but we were able to use only those with sufficient observations in both the time and cross-sectional dimensions (generally at least three comparable 5-year dates, depending on the nature of the cross sections within each year). We did collect, but were unable to perform analysis for, several other popular measures of institutions, such as central bank independence, government effectiveness, risk of expropriation, and judicial independence. Across all measures, 215 countries are represented over a 35-year window. The institutional measures capture different aspects of economic and political institutions, summarized as follows: ${ }^{4}$

Economic Freedom of the World. Economic freedom of the world (EFW) is a measure of a country's economic freedom. Each EFW score is calculated using 42 different measures to create an index ranking countries around the world. Economic freedom is measured in five different areas: (1) size of government, (2) legal structure and security of property rights, (3) access to sound money, (4) freedom to trade internationally, and (5) regulation of credit, labor, and business.

Political Rights. Political rights (PR) is a measure of the political rights held by citizens. The calculation of this variable is based on 10 political questions grouped into three subcategories: electoral process, political pluralism and participation, and functioning of government.

Civil Liberties. Civil liberties (CL) is a measure of the civil liberties held by citizens. The calculation of this variable is based on 15 political questions grouped into four subcategories: freedom of expression and belief, associational and organizational rights, rule of law, and personal autonomy and individual rights.

Constraints on the Executive. Constraints on the executive (EXEC) is a measure of the extent of institutionalized constraints on the decision-making powers of chief executives, whether individuals or collectives. Accountability may be executed by a variety of groups, including legislatures, an independent judiciary, ruling parties, councils of nobles or advisors, or the military. The main focus of this measure is the various checks and balances on the executive decisionmaking process.

Democracy. Democracy (DEM) is a measure of the degree of democracy in a given country based on the competitiveness of political participation, the openness and competitiveness of executive recruitment, and the constraints on the chief executive.

Autocracy. Autocracy (AUT) is a measure of the degree of autocracy in a given country based on the competitiveness of political participation, the regulation of political participation, the openness and competitiveness of executive recruitment, and the constraints on the chief executive.

\footnotetext{
${ }^{4}$ The different scales for these variables (even that "better" in some is a higher number but a lower number in others) are not problematic for our analysis because the cointegration analysis includes both the potential for a constant difference between the variables and either the positive or negative relationships.
} 
Table 2

Institutional Measures Used

\begin{tabular}{llc}
\hline Measure & \multicolumn{1}{c}{ Source } & $\begin{array}{c}\text { Maximum } \\
\text { Cross Section } \\
\text { of Countries }\end{array}$ \\
\hline Economic freedom of the world & Gwartney and Lawson (2008) & 130 \\
Political rights & Freedom House (2008) & 191 \\
Civil liberties & Freedom House (2008) & 191 \\
Constraints on the executive & Jaggers and Marshall (2000) & 128 \\
Democracy & Jaggers and Marshall (2000) & 128 \\
Autocracy & Jaggers and Marshall (2000) & 128 \\
Autocracy2 & Alvarez et al. (2000) & 134 \\
\hline
\end{tabular}

Autocracy2. Autocracy2 (AUT2) is a measure classifying regimes on the basis of their degree of autocracy. Countries are assigned to one of three categories: democracies, bureaucracies (dictatorships with a legislature), and autocracies (dictatorship without a legislature).

Consideration of these measures in the context of Williamson's hierarchy of social analysis, discussed in Section 2, provides insight regarding expected changes in institutions. Most of our measures of institutions map mainly to level 2, although some capture aspects of levels 1 and 3. The terms EXEC, DEM, AUT, and AUT2 clearly deal with the formal rules of political institutions and hence map neatly to level 2 of Williamson's hierarchy of social analysis. Some elements of EFW map to level 2 (for example, legal structure and security of property rights), while others map to level 3 (for example, size of government, soundness of money, and regulation). The former capture formal rules, including the structure of the legal system, while the latter consist of policies adopted in a given set of formal institutions.

The terms PR and CL differ from the other measures and therefore deserve additional explanation. They are not intended to be direct measures of government performance or formal political institutions. According to Freedom House, "The survey does not rate governments or government performance per se, but rather the real-world rights and social freedoms enjoyed by individuals. Freedoms can be affected by state actions, as well as by nonstate actors, including insurgents and other armed groups. Thus, the survey ratings generally reflect the interplay of a variety of actors, both governmental and nongovernmental" (Freedom House 2008). Although not serving as direct measures of democratic and government institutions, these measures capture important inputs of these institutions. Landman (2005, p. 48) notes "that Freedom House [the PR and CL indices] includes a wide range of institutional and rights concepts in its checklists, which are reflected in its overall scores." Because the PR and CL measures take a broader view of freedoms, they have elements that map to levels 1 and 2 of Williamson's hierarchy and therefore tend to be less likely to change.

For example, the PR measure includes suffrage and minority access and participation in the political process. Although these elements are clearly influenced 
by formal political rules, they are also largely affected by embedded institutions in terms of the rights that people possess. As history indicates, changes in suffrage or the rights of minorities can take significant time because they require broader society-wide changes in embedded perceptions and norms. Similarly, the PR measure includes perceptions of government corruption. Although government corruption is somewhat a matter of formal institutions-for example, institutional design and checks and balances-it is also a function of existing norms within the culture. Norms of intolerance toward corruption, including a willingness to punish corrupt behaviors, must exist among citizens. This means that although formal institutions are important, the ultimate outcome for corruption is largely a function of informal institutions in the form of culture, norms, and perceptions. The implication is that the questions associated with the PR measures capture elements of informal institutions located in level 1 of Williamson's hierarchy.

Likewise, the CL measure captures elements of cultural expression, private association, and religious and academic expression. Aron (2000, p. 109) notes that CL is a measure of social capital, a notion that includes trust, norms of reciprocity, and other embedded elements of social relations. These measures go beyond constraints on government and also focus on individuals outside the public arena. As such, they capture many elements of embedded informal institutions, including traditions, religion, and customs, and we would expect changes in these institutional measures to be slower or less likely to occur.

The implication of Williamson's hierarchy of social analysis for our empirical analysis is as follows: because institutions near the top of his hierarchy are slower to change and thus are more permanent, we are most likely to see evidence of stationarity (mean reversion) in the upper-level institutional measures. As we move down Williamson's hierarchy, it becomes increasingly likely to find evidence of nonstationarity (permanent changes).

\section{Testing for Stationarity in Institutional Measures}

Here we present the results of our statistical testing for whether these institutional measures are stationary (mean reverting) or nonstationary (unit root) processes. We conduct three panel unit root tests on each series: the Im, Pesaran, and Shin (2003) $W$-statistic, the augmented Dickey-Fuller $\chi^{2}$ test, and the Maddala and $\mathrm{Wu}$ (1999) Phillips-Perron $\chi^{2}$ test. A significant test statistic rejects the null hypothesis that the series has a unit root; thus, significant values indicate that the series is stationary. For institutional changes to be permanent, the series should be nonstationary or have an insignificant test statistic. Our results are presented in Table 3.

For four of the institutional measures, all three tests confirm nonstationarity: EXEC, DEM, AUT, and AUT2. The EFW index is nonstationary in two of the three tests, although the one and only significant result is significant only at the 10 percent level. Therefore, it is likely that EFW is also nonstationary. Changes 
Table 3

Panel Unit Root Tests for Institutional Measures

\begin{tabular}{lccll}
\hline Measure & IPS & ADF & MW/PP & Stationarity \\
\hline EFW & $-1.59^{+}$ & 212.81 & 204.26 & Nonstationary \\
PR & $-1.70^{* *}$ & $325.90^{* *}$ & $301.43^{* *}$ & Stationary \\
CL & $-3.80^{* *}$ & $317.03^{* *}$ & $322.50^{* *}$ & Stationary \\
EXEC & -.06 & 123.56 & 114.95 & Nonstationary \\
DEM & 1.96 & 75.65 & 83.19 & Nonstationary \\
AUT & -7.40 & 95.84 & 93.08 & Nonstationary \\
AUT2 & -.03 & 46.77 & 44.81 & Nonstationary \\
\hline
\end{tabular}

Note. All tests allow for heterogeneous dynamics (individual roots) and lag length selection by standard industrial classification and employ Newey-West bandwidth selection using the Bartlett kernel. Results for stationarity are for all tests unless indicated. IPS = Im, Pesaran, and Shan (2003) $W$-statistic; $\mathrm{ADF}=$ augmented Dickey-Fuller $\chi^{2} ; \mathrm{MW} / \mathrm{PP}=$ Maddala and Wu (1999) PhillipsPerron $\chi^{2}$ statistic.

${ }^{a}$ In two of three tests.

${ }^{+}$Statistically significant at the $10 \%$ level.

$* *$ Statistically significant at the $1 \%$ level.

or reforms to any of these institutions are predicted to become permanent. On the other hand, the results for the Freedom House measures of PR and CL are significant, which indicates that these series are stationary or mean reverting. According to our data analysis, changes or reforms to these series tend to die out, and with the passage of time, these institutions return to some predetermined mean value.

These results fit with the predictions of Williamson's hierarchy of social analysis and the discussion in Section 4. Given that PR and CL capture a variety of institutional concepts, including some informal embedded (level 1) elements, they are more likely to be stationary, or mean reverting, than the other institutional measures used in our analysis. Level 1 institutions take significant time to permanently change, and shocks to these institutions are likely to be temporary, with a return to the original mean. This is because informal embedded institutions "display a great deal of inertia-some because they are functional (such as conventions); others take on a symbolic value. . . . Many are pervasively linked with complementary institutions (formal and informal), etc." (Williamson 2000, p. 597). We believe that it is the embedded informal institutional elements captured in the PR and CL measures that underly our finding of mean reversion, or stationarity.

To provide a specific illustration of our results, consider the institutional measures for El Salvador. El Salvador is one of the many examples in the data that appears to show the simultaneous stationarity of PR and CL and nonstationarity of the other institutional measures (EFW, EXEC, DEM, AUT, and AUT2). Figures 3 and 4 show El Salvador's PR and CL indices.

After upward spikes in both of these series in 1980, both reverted to their original levels. The 2005 ending values for these series are identical to the initial 1975 values, despite both experiencing large shocks in 1980. This mean reversion illustrates the stationarity of these two measures. 


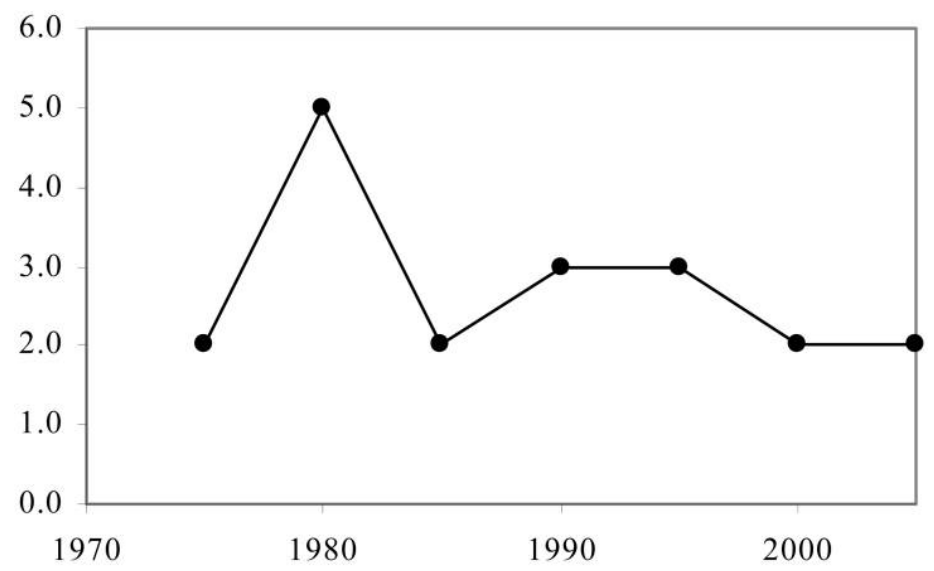

Figure 3. Stationary institutional measure for El Salvador: political rights

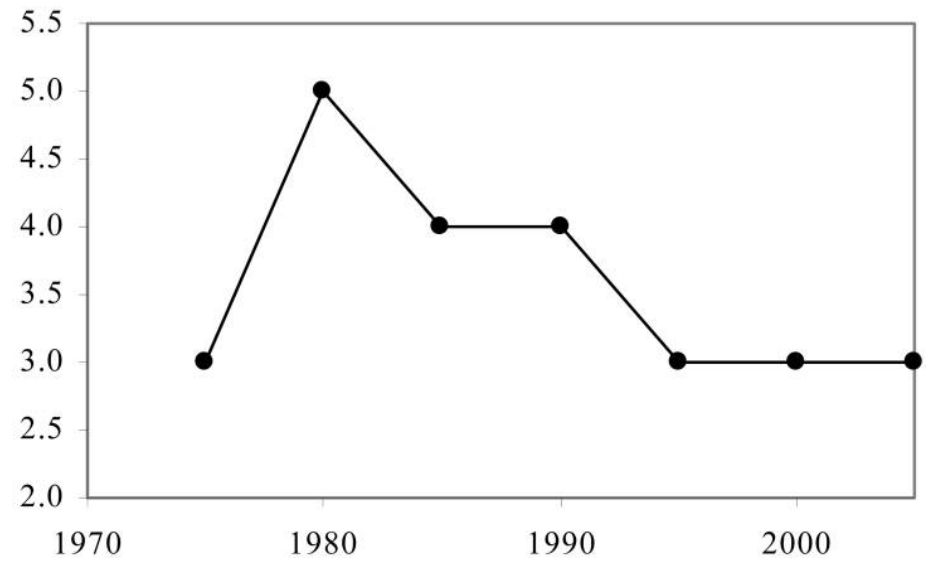

Figure 4. Stationary institutional measure for El Salvador: civil liberties

Figures 5-8 show El Salvador's other institutional measures, which all underwent changes that remained permanent (that is, the changes do not revert with time). The upward spike in EFW (Figure 5) in 1995, for example, remained permanent, as did the upward spikes in EXEC (Figure 6) and DEM (Figure 7) in 1985 and the downward spikes in AUT and AUT2 (Figure 8) in 1985. For all four of the institutional measures illustrated, the changes were permanently incorporated into the series, in contrast with the institutional measures illustrated in Figures 3 and 4, where the changes were only temporary. These are precisely 


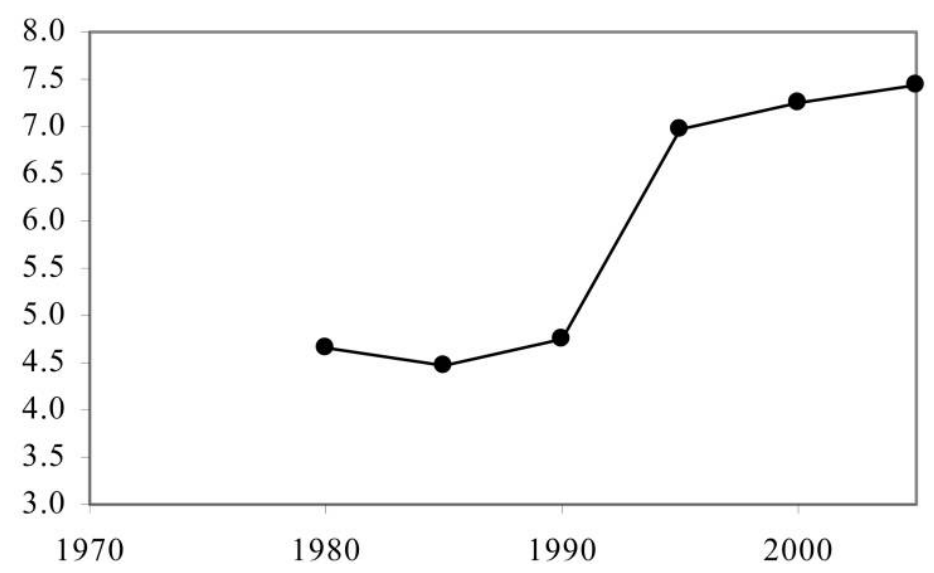

Figure 5. Nonstationary institutional measure for El Salvador: economic freedom of the world.

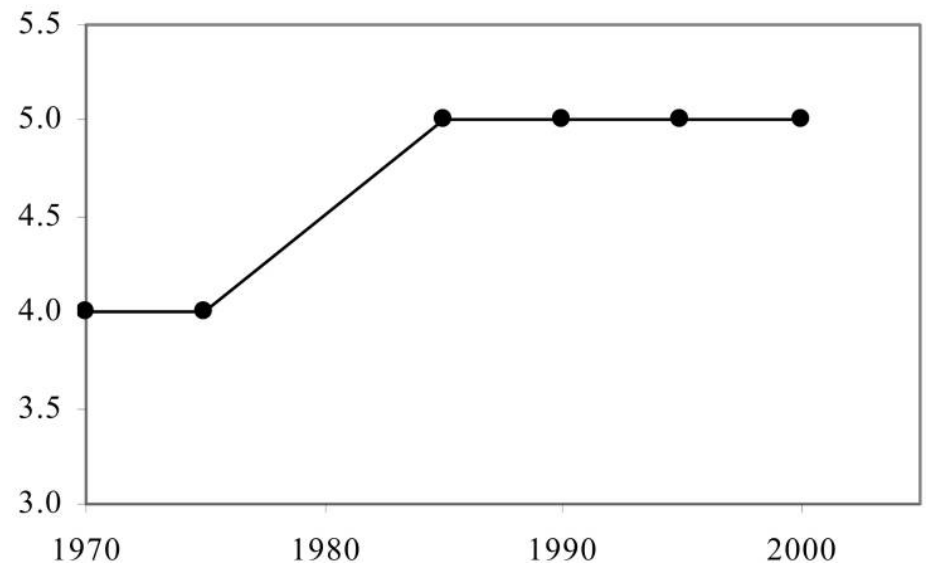

Figure 6. Nonstationary institutional measure for El Salvador: constraints on the executive

the patterns for stationary and nonstationary time series given in the hypothetical examples (illustrated in Figures 1 and 2) previously discussed.

\section{Testing for Cointegration across Institutional Measures}

In this section, we present our results of the pairwise cointegration tests between the institutional measures. For two series to be cointegrated requires that they both be individually nonstationary but that there exist a linear combination 


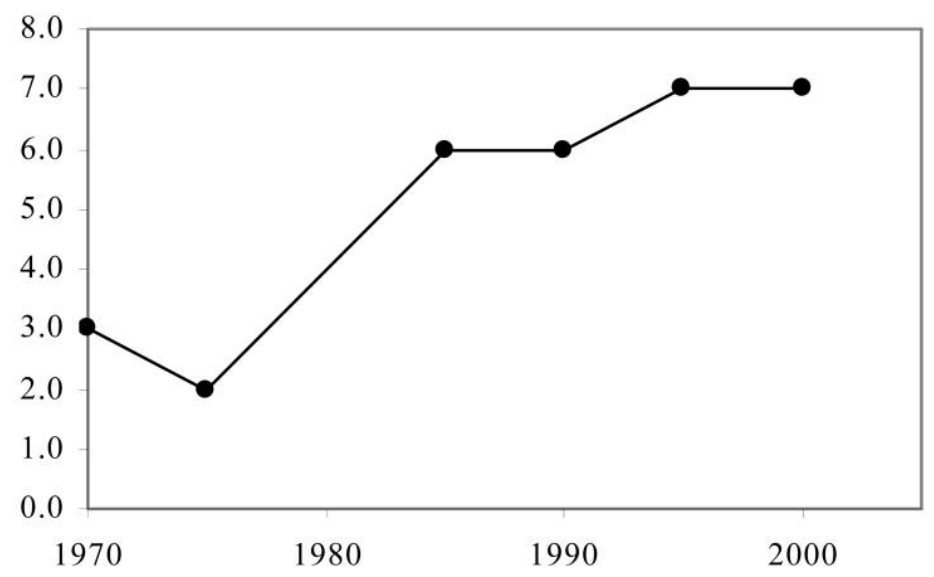

Figure 7. Nonstationary institutional measure for El Salvador: democracy

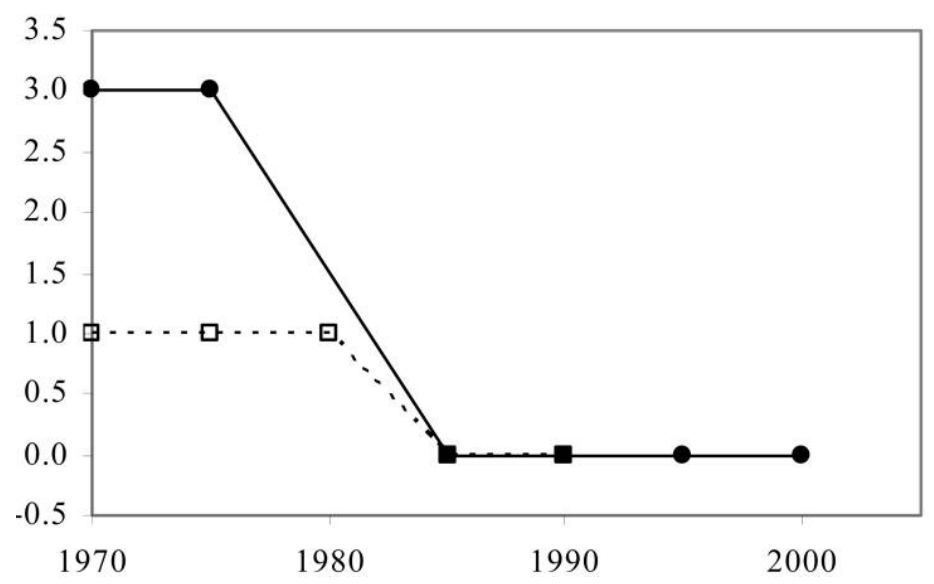

Figure 8. Nonstationary institutional measures for El Salvador: autocracy (solid line) and autocracy 2 (dashed line).

of the two that is stationary. ${ }^{5}$ Therefore, because PR and CL were found to be stationary, they are excluded from our cointegration tests. ${ }^{6}$ Our pairwise panel

${ }^{5}$ Table A1 presents the unit root tests performed on the first differenced series, and in all cases we can reject the presence of a second unit root in these series.

${ }^{6}$ Because they were borderline nonstationary, we did perform cointegration tests using PR and $\mathrm{CL}$ and found them to be cointegrated (although generally with lower test statistic values) with all of the other institutional measures. Thus, within our sample period, the changes among the various formal institutions are more closely correlated with one another than they are with the changes in informal institutions. However, the extended long-term paths of a country's formal and informal institutions are indeed intertwined over extremely long periods. 
Table 4

Pairwise Panel Cointegration Tests among Institutional Measures

\begin{tabular}{ccccc}
\hline & EXEC & DEM & AUT & AUT2 \\
\hline PP- $\rho$ test: & & & & \\
EFW & 5.09 & 4.97 & 5.80 & 3.20 \\
EXEC & & 5.95 & 6.66 & 2.77 \\
DEM & & & 6.48 & 3.26 \\
AUT & & & & 3.21 \\
PP test: & & & & \\
EFW & -4.55 & -7.65 & -5.82 & -5.50 \\
EXEC & & -8.63 & -8.06 & -7.41 \\
DEM & & & -9.19 & -3.27 \\
AUT & & & & -5.15 \\
ADF test: & & -6.18 & -4.86 & -4.99 \\
EFW & -4.23 & -7.79 & -7.89 & -6.58 \\
EXEC & & & -3.70 & \\
DEM & & & & -6.08 \\
AUT & & & & \\
\hline
\end{tabular}

Note. All tests allow for heterogeneous dynamics (individual roots) and lag length selection by standard industrial classification and employ Newey-West bandwidth selection using the Bartlett kernel. All values are significant at the $1 \%$ level. Although a test for simultaneous cointegration of all five measures could not be performed, after dropping the one with the fewest observations (AUT2), the remaining four measures (AUT, EXEC, DEM, and EFW) are all mutually cointegrated. For the nonparametric Phillips-Perron $\rho$ test, PP- $\rho=4.30(p=1 \%)$; for the nonparametric Phillips-Perron test, $\mathrm{PP}=-5.40(p=1 \%)$; and for the augmented Dickey-Fuller test, $\mathrm{ADF}=-3.77$ $(p=1 \%)$.

cointegration tests for the remaining nonstationary institutional measures are shown in Table 4.

Three cointegration tests are performed, all according to Pedroni (1999, 2004). They are the nonparametric Phillips-Perron group $\rho$ test, the nonparametric Phillips-Perron group test, and the group augmented Dickey-Fuller test. A significant test statistic rejects the null of no cointegration; therefore, significant values indicate that the two series are cointegrated and that they move together through time. In each and every pairwise comparison, these institutional measures show clear evidence of cointegration in all three tests. Therefore, it is possible to conclude that, indeed, all of these institutional measures are cointegrated and thus move together within a country through time. There are longterm ties among and between all of these economic and political institutions that cause them to move, over the long run, in unison.

This finding supports both the theoretical and empirical literature regarding institutions and economic growth. In their analysis of the emergence and sustainability of political and economic systems, North, Wallis, and Weingast (2009) contend that the two systems help sustain each other. They develop a theory of double balance in which political and economic institutions each have their own equilibrium and in which, in addition, the relationship between the two systems also has its own unique equilibrium. They conclude that this double balance implies that sustainable change to either system must be accompanied by fun- 


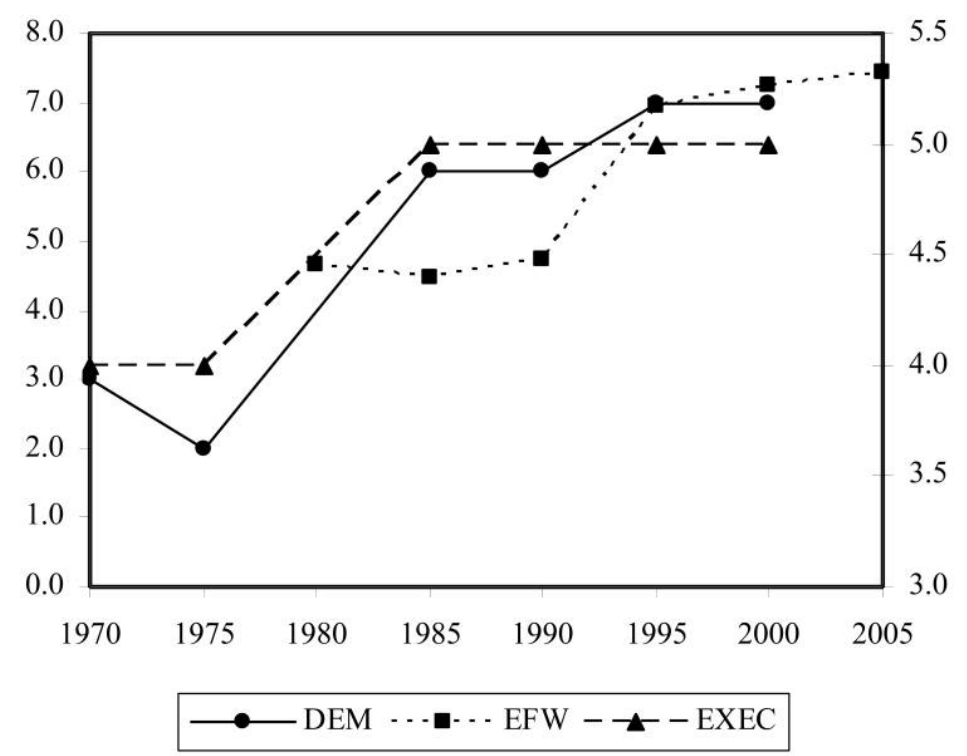

Figure 9. El Salvador's cointegrated institutions

damental changes in the other system. Rodrik (2007, pp. 35-44) indicates empirically that generating quick growth spurts is often associated with a narrow set of institutional and policy changes. However, sustainable growth must be accompanied by extensive institutional reform across economic and political institutions. For growth to be sustainable, changes that provide an incentive for productive entrepreneurship and the efficient allocation of resources must be institutionalized. Absent deeper reform, marginal changes will tend to unravel. Along these lines, Rodrik (2007, p. 43) concludes that "the key to longer-term prosperity, once growth is launched, is to develop institutions that maintain productive dynamism and generate resilience to external shocks."

Again, to illustrate the specific implications of our findings, we return to the data for El Salvador. The fact that a country's EFW, EXEC, DEM, AUT, and AUT2 measures are cointegrated means that over long periods they tend to move together. Figure 9 shows several of these measures for El Salvador. ${ }^{7}$

Clearly, over this 35-year period, all of these measures have moved together, and clearly there were periods (such as 1985-90) when they were more divergent from each other and subsequently corrected this differential. The data illustrate that these institutions move together over the long term within a country, despite short-term differentials at any given cross-sectional moment.

${ }^{7}$ All of El Salvador's cointegrated institutional measures demonstrate our point. We present just three measures here to make the figure easier to examine (see Figure 8 for AUT and AUT2). 
Table 5

Pairwise Panel Cointegration Tests among Economic Freedom of the World Areas

\begin{tabular}{lcrrr}
\hline & Area 2 & Area 3 & Area 4 & Area 5 \\
\hline PP- $\rho$ test: & & & & \\
Area 1: size of government & 8.70 & 9.10 & 8.43 & 9.05 \\
Area 2: property rights & & 7.14 & 6.26 & 6.66 \\
Area 3: money & & & 7.34 & 8.04 \\
Area 4: international trade & -3.41 & -7.92 & -5.65 & -6.03 \\
PP test: & & -15.16 & -14.77 & -15.79 \\
Area 1: size of government & & & -9.63 & -10.17 \\
Area 2: property rights & & & -11.23 \\
Area 3: money & -2.32 & -5.68 & -3.59 & -4.94 \\
Area 4: international trade & & -12.39 & -11.94 & -12.96 \\
ADF test: & & & -8.01 & -8.41 \\
Area 1: size of government & & & -10.50 \\
Area 2: property rights & & & & \\
Area 3: money & & & & \\
Area 4: international trade & & & & \\
\hline
\end{tabular}

Note. Test statistics are from Pedroni $(1999,2004)$. A significant test statistic rejects the null of no cointegration; thus, significant values indicate that the two series are cointegrated. All tests allow for heterogeneous dynamics (individual roots) and lag length selection by standard industrial classification and employ Newey-West bandwidth selection using the Bartlett kernel. All values are significant at the $1 \%$ level. Area $5=$ regulation of credit, labor, and business.

One somewhat tangential but interesting question is whether the subcomponent areas of the EFW index are cointegrated. The index is composed of five subareas, including (1) size of government (expenditures, taxes, and enterprises), (2) legal structure and security of property rights, (3) access to sound money, (4) freedom to trade internationally, and (5) regulation of credit, labor, and business. One reason why this question is of interest is that in simple crosssectional analysis, depending on the year used, there are counterintuitive negative cross-sectional correlations that sometimes appear. We first tested each EFW subarea for stationarity and found that area 2 is stationary, while areas $1,3,4$, and 5 are nonstationary. We therefore exclude area 2 from the cointegration tests. Table 5 presents the results of these three cointegration tests among the nonstationary subcomponent areas of the EFW index. Note that although area 1 has no column (and area 5 has no row), all possible combinations for these two areas are shown.

Similar to the results for most of the institutional measures, we again find that the four subareas of the EFW index are pairwise cointegrated. Therefore, economic reforms to the size of government, legal structure and property rights, monetary policy, international trade, and regulation are not independent phenomena. Meaningful reforms to any one of these institutions can happen only as part of a broader increase in all areas of economic freedom. ${ }^{8}$

One explanation why so many of a country's economic and political insti-

${ }^{8}$ In addition, we performed a test to determine if the four subareas, jointly, were cointegrated, and they were. 
tutions are cointegrated is that when changes to institutions become politically and socially feasible in one area, they also tend to simultaneously become possible in other areas as well. A shift in the median voter's preferences or ideology, a change in the ruling party in power, or the collapse of existing formal institutions tend to lead to widespread changes across many institutions. It is unlikely that a country would be in a situation to enact major reforms to one institution without other similar opportunities being present for other institutions. Evidence from transition countries indicates a snowball effect whereby even marginal reforms to one institution can be reinforcing and can result in subsequent reforms to other institutions (Brezis and Verdier 2003). For example, Fidrmuc (2003) finds that political liberalization in transition countries reinforces economic liberalization.

\section{Conclusion}

Although a large empirical literature has examined measures of countries' institutions and their links to growth and prosperity (and to each other) using cross-sectional data, we perform the first serious time-series investigation of these measures using modern panel unit root and cointegration analysis. This analysis yields several new and interesting insights into these institutions and their interrelationships.

First, we find that most of a country's formal political and economic institutions are nonstationary, which implies that institutional reforms and changes can indeed be permanently maintained. The exceptions to this finding are rightsbased measures of a country's institutions, which contain embedded informal elements such as norms and traditions. We find these institutions to be stationary and mean reverting, which means that they are more permanent, and changes tend to be only temporary, with the series reverting back to its prior level. Thus, although it may be possible to achieve permanent institutional reform in many areas, some underlying institutions in countries appear to be predetermined by long-standing and permanent social and cultural norms. This is consistent with Williamson's (2000) hierarchy of levels of social analysis and the time required for sustainable change at each level.

Second, we find clear evidence that all of a country's nonstationary institutions are cointegrated. This suggests that there are long-term ties between formal political and economic institutions, such as economic freedom, constraints on the executive, democracy, and autocracy, which implies that they all tend to move together through time within a country. It also suggests that reforms to one set of institutions likely will not hold unless other institutions are simultaneously reformed as well. Had these nonstationary institutions not been cointegrated, it would have implied that each could be changed permanently, independently of the other institutions. Thus, this finding of cointegration suggests that institutional reform may be more difficult than it appears because it requires simultaneous broader reforms in the entire set of institutions in the country. The 
overall size of a country's government sector, the degree of regulation or taxation, the extent of democracy, and political constraints are intertwined and must be reformed together to result in permanent and meaningful institutional reform. This has implications for external efforts to encourage specific institutions reforms through such mechanisms as conditional foreign aid, state building, and economic reconstruction.

It has been suggested that a country's formal political and economic institutions are outgrowths of underlying informal institutions embodied within cultural norms. If a common set of informal institutions underlies all of a country's formal institutions, there is good reason to believe theoretically that they all should be cointegrated. This is the underlying logical explanation for our empirical results.

This also helps to explain Olson's (1982) finding that large shocks (for example, wars, revolutions, and economic crises) create opportunities for successful permanent institutional change within a country. When these shocks occur, there is a disruption of the power structure among existing vested interests, and simultaneous change across multiple political and economic institutions becomes feasible. For example, the devastation resulting from World War II led to dramatic changes in the fundamental structure of a vast array of political and economic institutions in Japan and Germany. Similar logic can be applied to other crises as well, including the permanence and institutional breadth of New Deal reforms and the current widespread institutional responses to the events of September 11, 2001, and the recent financial crisis.

Third, our use of panel time-series techniques is uniquely suited to address the questions of institutional permanence and interrelation. Simple cross-sectional analysis cannot uncover these long-term facets of the data and suffers from problems associated with cointegrated variables that are temporarily shocked out of their long-term relationships. One troubling implication of our analysis is that because the vast majority of country institutional measures are nonstationary, they should not be used (in levels) as independent variables in a regression with other nonstationary variables (such as measures of prosperity). Such regressions will produce spurious correlations. The reason that this is troubling is that there now is a large literature that uses these measures in precisely this (incorrect) method. These nonstationary institutional measures can be used in first-difference form (that is, the change in the series); however, without incorporating additional terms into the regression to account for the cointegrating dynamics (such as an error correction model), they will also suffer from bias. The failure of the previous empirical institutional literature to properly account for the time-series properties of these measures calls many of its results into question.

Finally, and perhaps most important, the fact that all of these institutional measures are cointegrated suggests that it will be impossible to determine which of a country's many institutions is the one responsible for economic prosperity. As the data for El Salvador show, many of the country's institutions have changed 
together, and it would be impossible to attribute changes in economic performance to a single institution. Many institutions move together through time, and it is this simultaneous movement that results in changes in economic performance.

Over the long run, we would not expect to see many cases of mismatchesa country will generally have all good, all middling, or all weak institutions. In the long run, countries with good institutions in one area will have them in others as well. This does not imply that short-term cases of mismatched institutions cannot or will not exist, nor does it serve as evidence that the two institutions are not truly related.

The hunt for which institutions (for example, political constraints, autocracy, democracy, capitalism, and quality of institutions) are the true factors behind growth will never and can never be solved empirically because of the fact that they are cointegrated. Any, and all, of the cointegrated institutional measures will be related to prosperity when examined individually, and in any given cross section, one set of institutions may appear to be more important than others simply because of spurious short-term departures from the long-term cointegrating paths that these institutions follow.

\section{Appendix}

Table A1

Panel Unit Root Tests for the First-Differenced Series of Institutional Measures: Tests for a Second Unit Root

\begin{tabular}{lccc}
\hline & IPS & ADF & MW/PP \\
\hline$\Delta$ EFW & -13.03 & 505.63 & 687.73 \\
$\Delta$ PR & -8.89 & 453.19 & 609.06 \\
$\Delta$ CL & -7.93 & 461.40 & 587.23 \\
$\Delta$ EXEC & -3.74 & 130.88 & 171.28 \\
$\Delta$ DEM & -3.57 & 127.46 & 166.70 \\
$\Delta$ AUT & -3.46 & 147.52 & 191.36 \\
$\Delta$ AUT2 & -2.15 & 59.65 & 68.40 \\
\hline
\end{tabular}

Note. All values are significant at the $1 \%$ level. A significant test statistic rejects the null hypothesis that the first-differenced series has a unit root; thus, significant values indicate the absence of a second unit root (in all tests). All tests allow for heterogeneous dynamics (individual roots) and lag length selection by standard industrial classification and employ Newey-West bandwidth selection using the Bartlett kernel. IPS = Im, Pesaran, and Shin (2003) W-statistic; $\mathrm{ADF}=$ augmented Dickey-Fuller $\chi^{2}$ test statistic; MW/PP = Maddala and Wu (1999) Phillips-Perron $\chi^{2}$ test statistic.

\section{References}

Acemoglu, Daron, and Simon Johnson. 2005. Unbundling Institutions. Journal of Political Economy 115:949-95.

Acemoglu, Daron, Simon Johnson, and James Robinson. 2001. The Colonial Origins of Comparative Development: An Empirical Investigation. American Economic Review 91: 1369-1401. 
2002. Reversal of Fortunes: Geography and Institutions in the Making of the Modern World Income Distribution. Quarterly Journal of Economics 117:1231-94.

Alvarez, Michael, José A. Cheibub, Fernando Limongi, and Adam Przeworski. 2000. Democracy and Development: Political Institutions and Material Well-Being in the World, 1950-1990. Cambridge: Cambridge University Press.

Anderson, Terry L., and Peter J. Hill. 2004. The Not So Wild, Wild West. Stanford, Calif.: Stanford University Press.

Aron, Janine. 2000. Growth and Institutions: A Review of the Evidence. World Bank Research Observer 15:99-135.

Barro, Robert J. 1996. Democracy and Growth. Journal of Economic Growth 1:1-27.

Barro, Robert J., and Rachel McCleary. 2003. Religion and Economic Growth across Countries. American Sociological Review 68:760-81.

Boettke, Peter J., Christopher J. Coyne, and Peter T. Leeson. 2008. Institutional Stickiness and the New Development Economics. American Journal of Economics and Sociology 67:331-58.

Brezis, Elise S., and Thierry Verdier. 2003. Political Institutions and Economic Reforms in Central and Eastern Europe: A Snowball Effect. Economic Systems 27:289-311.

Coase, R. H. 1960. The Problem of Social Cost. Journal of Law and Economics 3:1-44.

Demsetz, Harold. 1967. Toward a Theory of Property Rights. American Economic Review 57:347-59.

de Soto, Hernando. 1989. The Other Path. New York: Basic Books.

Dixit, Avinash K. 2004. Lawlessness and Economics: Alternative Modes of Governance. Princeton, N.J.: Princeton University Press.

Easterly, William. 2001. Can Institutions Resolve Ethnic Conflict? Economic Development and Cultural Change 49:687-706.

Fidrmuc, Jan. 2003. Economic Reform, Democracy and Growth during Post-Communist Transition. European Journal of Political Economy 19:583-604.

Freedom House. 2008. Freedom in the World Index. Washington, D.C.: Freedom House. http://www.freedomhouse.org/template.cfm?page $=351 \&$ ana_page $=341$ \&year $=2008$.

Friedman, Milton. 1962. Capitalism and Freedom. Chicago: University of Chicago Press.

Gallup, John, Jeffrey Sachs, and Andrew Mellinger. 1999. Geography and Economic Development. International Regional Science Review 22:179-232.

Glaeser, Edward, Rafael La Porta, Florencio Lopez-de-Silanes, and Andrei Shleifer. 2004. Do Institutions Cause Growth? Journal of Economic Growth 9:271-303.

Green, William H. 2008. Econometric Analysis. 6th ed. Upper Saddle River, N.J.: Pearson Prentice Hall.

Grier, Robin. 1997. The Effect of Religion on Economic Development: A Cross-National Study of Sixty-Three Former Colonies. Kyklos 50:47-62.

Guiso, Luigi, Paola Sapienza, and Luigi Zingales. 2006. Does Culture Affect Economic Outcomes? Journal of Economic Perspectives 20(2):23-48.

Gwartney, James D., and Robert A. Lawson. 2008. Economic Freedom of the World. Vancouver: The Fraiser Institute.

Gwartney, James D., Robert A. Lawson, and Randall G. Holcombe. 1999. Economic Freedom and the Environment for Economic Growth. Journal of Institutional and Theoretical Economics 155:1-21.

Hayek, F. A. 1944. The Road to Serfdom. Chicago: University of Chicago Press.

Im, Kyung So., M. Hashem Pesaran, and Yongcheol Shin. 2003. Testing for Unit Roots in Heterogeneous Panels. Journal of Econometrics 115:53-74. 
Jaggers, Keith, and Monty G. Marshall. 2000. Polity IV Project. Center for International Development and Conflict Management, University of Maryland, College Park.

Knack, Stephen, and Philip Keefer. 1997. Does Social Capital Have an Economic Payoff? A Cross-Country Investigation. Quarterly Journal of Economics 112:1251-88.

Kornai, Janos. 1992. The Socialist System: The Political Economy of Communism. London: Oxford University Press.

. 1998. From Socialism to Capitalism. London: Center for Post-Collectivist Studies.

Landman, Todd. 2005. Protecting Human Rights: A Comparative Study. Washington D.C.: Georgetown University Press.

Leeson, Peter T. 2007. Trading with Bandits. Journal of Law and Economics 50:303-21. $161-81$. 2008. Social Distance and Self-Enforcing Exchange. Journal of Legal Studies 37: 2009. The Laws of Lawlessness. Journal of Legal Studies 38:471-503.

Maddala, G. S., and Shaowen Wu. 1999. A Comparative Study of Unit Root Tests with Panel Data and New Simple Test. Oxford Bulletin of Economics and Statistics 61:631-52.

Matthews, R. C. O. 1986. The Economics of Institutions and the Sources of Growth. Economic Journal 96:903-18.

Mehlum, Halvor, Karl Moene, Ragnar Torvik. 2006. Institutions and the Resource Curse. Economic Journal 116:1-20.

North, Douglass. 1990. Institutions, Institutional Change and Economic Performance. Cambridge: Cambridge University Press. . 1991. Institutions. Journal of Economic Perspectives 5(1):97-112.

2005. Understanding the Process of Economic Change. Princeton, N.J.: Princeton University Press.

North, Douglass C., and Robert Paul Thomas. 1973. The Rise of the Western World. Cambridge: Cambridge University Press.

North, Douglass C., John J. Wallis, and Barry R. Weingast. 2009. Violence and Social Orders: A Conceptual Framework for Interpreting Recorded Human History. Cambridge: Cambridge University Press.

Olson, Mancur. 1982. The Rise and Decline of Nations. New Haven, Conn: Yale University Press.

Ovaska, Tomi, and Russell S. Sobel. 2005. Entrepreneurship in Post-Socialist Economies. Journal of Private Enterprise 21:8-28.

Pedroni, Peter. 1999. Critical Values for Cointegration Tests in Heterogeneous Panels Multiple Regressors. Oxford Bulletin of Economics and Statistics 61:653-70.

. 2004. Panel Cointegration: Asymptotic and Finite Sample Properties of Pooled Time Series Tests, with an Application to the PPP Hypothesis. Econometric Theory 20: 597-625.

Rodrik, Dani. 2007. One Economics Many Recipes: Globalization, Institutions, and Economic Growth. Princeton, N.J.: Princeton University Press.

Rodrik, Dani, Arvind Subramanian, and Francesco Trebbi. 2004. Institutions Rule: The Primacy of Institutions over Geography and Integration in Economic Development. Journal of Economic Growth 9:131-65.

Sachs, Jeffrey. 2003. Institutions Don't Rule: Direct Effects of Geography on per Capita Income. Working Paper No. 9490. National Bureau of Economic Research, Cambridge, Mass.

Sachs, Jeffrey, and Andrew Warner. 2001. The Curse of Natural Resources. European Economic Review 45:827-38. 
Smith, Adam. [1776] 1904. An Inquiry into the Nature and Causes of the Wealth of Nations, edited by Edwin Cannan. 5th ed. London: Methuen \& Co.

Sobel, Russell S., J. R. Clark, and Dwight R. Lee. 2007. Freedom, Barriers to Entry, Entrepreneurship, and Economic Progress. Review of Austrian Economics 20:221-36.

Stewart, Dugald. 1793. Account of the Life and Writings of Adam Smith, L.L.D. Edinburgh: Royal Society of Edinburgh.

Williamson, Claudia R. 2009. Informal Institutions Rule: Institutional Arrangements and Economic Performance. Public Choice 139:371-87.

Williamson, Oliver E. 1975. Markets and Hierarchies. New York: Free Press.

. 2000. The New Institutional Economics: Taking Stock, Looking Ahead. Journal of Economic Literature 38:595-613. 